\title{
IMPROVEMENT OF MARINA DESIGN TECHNOLOGY USING HYDRODYNAMIC MODELS
}

\section{STAMOU* \\ I. K. KATSIRIS \\ C. I. MOUTZOURIS \\ V. K. TSOUKALA}

Department of Water Resources,

Hydraulic and Maritime Engineering,

National Technical University of Athens

5, Iroon Polytechniou Street, Zografou 15573, Greece

*to whom all correspondence should be addressed:

Tel: + (30) 2107722809,

Received: 02/06/03

Accepted: 02/03/04

e-mail: stamou@central.ntua.gr

\begin{abstract}
A mathematical model is applied to calculate the water circulation in the marina of Latsi in Cyprus. The flow field in the marina shows the general behavior of coastal, wind driven flows, being strongly influenced by the characteristics of the entrance of the marina. The small dimension and the location of the entrance do not permit the inflow or outflow of significant flow rates, thus resulting to long flushing times. The use of two openings has been investigated. Computations show that the first opening plays a very important role, while the effect of the second opening is only of local and minor importance. This behavior is due to the orientation and the position of these openings with respect to the entrance. The use of the first opening results to a significant increase of the flow-rate passing through the inner part of the marina, which increases the magnitude of the velocities and reduce the flushing times. The use of the second opening leads to a significant short-circuiting path of the flow between the opening and the entrance. The first opening has been proposed for construction.
\end{abstract}

KEYWORDS: mathematical model, marina, flushing, flushing time, residence time, Latsi

\section{INTRODUCTION}

Previous decades have been characterized by an increase in marine tourism. This increase has led to the construction of new marinas or the expansion of existing ones. Boats in marinas usually release small amounts of pollutants. When these amounts are multiplied by hundreds of boaters and marinas, they can cause distinct water quality problems in coastal waters. The following potential environmental impacts from boating and marinas have been identified (EPA, 1996; EPA,
2001): high toxicity in the water, increased pollutant concentrations in aquatic organisms and sediments, increased erosion rates, increased nutrients, leading to an increase in algae and a decrease in DO concentration (eutrophication) and high levels of pathogens. In addition, construction at marinas can lead to the physical destruction of sensitive ecosystems and bottomdwelling aquatic communities.

Water pollution in marinas is linked to several sources. They include (1) poorly flushed water- 
ways, (2) unsatisfactory boat maintenance, (3) discharge of sewage from boats, (4) storm water runoff from marina parking lots and (5) physical alteration of shoreline, wetlands, and aquatic habitat during the construction and operation of marinas.

To reduce water pollution, marinas should be located, designed, built and maintained to be harmonious with water quality, fish and wildlife habitat as well as the ecosystem (EPA, 1993a). Potential negative impacts related to marinas (e.g. habitat destruction, especially in ecologically sensitive areas) can be avoided, mitigated or significantly reduced by environmentally conscious development and planning, observance of recommended environmental best management practices and adherence to environmental regulations. Water quality in a marina depends largely on how well the basin is flushed, which depends in turn on how well water circulates inside the marina. Studies have shown that adequate flushing improves water quality, reduces or eliminates water stagnation and helps maintain biological productivity and aesthetic appeal (Schwartz, 1989; Schwartz and Imberger, 1988). Flushing may reduce pollutant concentrations in a marina basin by $70 \%$ to $90 \%$ over a 24 -hour period (Cardwell and Koons, 1981; Tetra Tech, 1988).

Marina flushing can be estimated with the use of the "mean flushing time" or "residence time", which is defined as the average length of time a contaminant from a particular source remains within the water body (Officer, 1976; Fisher et al., 1979). Flushing time can be determined with the use of field studies and analyses (tracers) and/or sophisticated numerical models (Hilton et al., 1998; Stamou et al., 1997; Yin et al., 1998; Stamou et al., 2001). The mathematical models calculate water circulation in marinas taking into account wind driven and /or tidal effects.

Flushing times can range from zero days for marinas boundaries adjacent to the open sea to several weeks within the marina basin at secluded locations, or where in water structures prevent water from circulations (EPA, 1993b). Water quality in marinas can be improved with the use of mechanical devices, such as mechanical aerators or by proper design (e.g. use of openings), which reduce flushing times and avoid areas of low flow and eddies formation.

In the present work a mathematical model is applied to assess the effect of two openings in the marina of Latsi in Cyprus, which is in the phase of design. Wind driven flow fields and flushing times are calculated for various scenarios of wind velocities and directions with and without openings.

\section{THE MODEL}

The mathematical model CFX-5 (AEA Technology, 1999) calculates the 3-D steady-state flow field from the solution of the equations of continuity and momentum. The model employs unstructured and structured numerical grids, which permit a very accurate representation of the boundaries. The algebraic equations are derived using second order spatial discretisation schemes and are solved in a coupled fashion with a fast and robust procedure.

The source terms of the momentum equations have been modified to take into account the effect of wind. Two terms have been added, which represent the vertical shears at the surface, $\tau_{\mathrm{sx}}$ and $\tau_{\mathrm{sy}}$, in the direction $\mathrm{x}$ and $\mathrm{y}$, respectively by the following equations:

$$
\frac{\tau_{\mathrm{sx}}}{\varrho}=C_{s} \mathrm{u}_{10} \sqrt{\mathrm{u}_{10}^{2}+\mathrm{v}_{10}^{2}} \text { and } \frac{\tau_{\mathrm{sy}}}{\varrho}=C_{s} \mathrm{v}_{10} \sqrt{\mathrm{u}_{10}^{2}+\mathrm{v}_{10}^{2}}
$$

where $\mathrm{u}_{10}$ and $\mathrm{v}_{10}$ are the wind velocity components at a $10 \mathrm{~m}$ height from the surface along axes $\mathrm{x}$ and $\mathrm{y}$, respectively, and $\mathrm{C}_{\mathrm{s}}$ is the shear stress coefficient at the surface. In the present work $\mathrm{C}_{\mathrm{s}}$ is taken equal to $2,46 \times 10^{-6}$ (Stamou et al., 2001).

The Coriolis force has been ignored due to the relatively small size of the calculation domain.

\section{APPLICATION OF THE MODEL - RESULTS AND DISCUSSION The area and scope of the study}

The model is applied to the marina of Latsi, located on the northwest of Cyprus. In Fig.1 the area of study is shown, which consists of the following sub-domains: (a) the region of the marina (internal and outer), which covers a region of approximately $1 \mathrm{~km} \times 0.5 \mathrm{~km}$, and (b) the wider coastal area. The internal region, which communicates with the outer region via the entrance (ENT), consists of 3 compartments, numbered as 1, 2 and 3 in Fig. 1. These compartments communicate with each other via the openings 1-2 and 2-3. The water depths of these compartments are equal to $2.50 \mathrm{~m}, 3.50 \mathrm{~m}$ and $3.50 \mathrm{~m}$, and the 


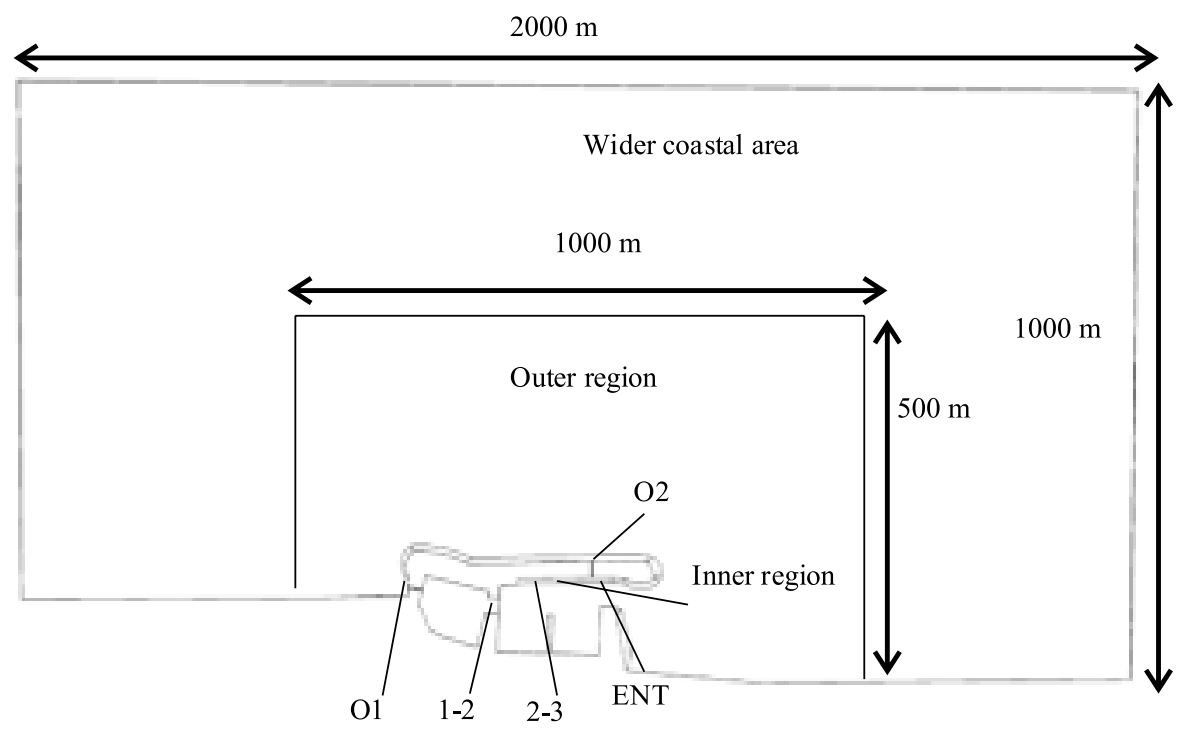

Figure 1. Top view of the computation domain

volumes equal to $\mathrm{V}_{1}=30300 \mathrm{~m}^{3}, \mathrm{~V}_{2}=37200 \mathrm{~m}^{3}$ and $V_{3}=38400 \mathrm{~m}^{3}$, respectively. The total water volume of the marina is equal to $\mathrm{V}=$ $\mathrm{V}_{1}+\mathrm{V}_{2}+\mathrm{V}_{3}=105900 \mathrm{~m}^{3}$.

In its present status, the marina consists only of compartment 1 , which has a capacity of berthing 80 boats. The Ministry of Transportation and Public Works of Cyprus is planning to extend the marina by adding the compartments 2 and 3, shown in Fig.1, which have an additional capacity of 120 boats. This extension is expected to create significant water flushing problems, especially in the existing compartment 1 . To face these problems in the phase of the design, the Ministry of Transportation and Public Works has decided to assign to the Laboratory of Harbor Works, National Technical University of Athens (NTUA) the study of the extension of the marina with physical model. Among several alternative modifications, the construction of two openings has been considered as the simplest and most economical modification. These openings, which have a rectangular cross-section with width equal to $2.00 \mathrm{~m}$ and water height equal to $1.00 \mathrm{~m}$, are denoted in Fig.1 as O1 and O2. To examine the effect of these openings on the water flushing, flow field calculations have been performed in the Laboratory of Applied Hydraulics of the NTUA.

\section{Calculations}

Four series of calculations, noted as S1, S2, S3 and $\mathrm{S} 4$ in Table 1, have been performed for the characteristics (wind magnitude and direction) of the prevailing winds. These series have been repeated, noted as S1R, S2R, S3R and S4R in Table 1, with the openings.

Table 1. Series of calculations

\begin{tabular}{|c|c|c|c|c|}
\hline Series & Wind direction & Openings & $\mathbf{U}_{\mathbf{1 0}}\left(\mathbf{m} \mathbf{s e c}^{-\mathbf{1}}\right)$ & $\mathbf{V}_{\mathbf{1 0}}\left(\mathbf{m} \mathbf{s e c}^{-\mathbf{1}}\right)$ \\
\hline S1 & NE & No & $-2,12$ & $-2,12$ \\
\hline S2 & NW & No & 2,12 & $-2,12$ \\
\hline S3 & E & No & $-3,00$ & 0,00 \\
\hline S4 & W & No & 3,00 & 0,00 \\
\hline S1R & NE & Yes & $-2,12$ & $-2,12$ \\
\hline S2R & NW & Yes & 2,12 & $-2,12$ \\
\hline S3R & E & Yes & $-3,00$ & 0,00 \\
\hline S4R & W & Yes & 3,00 & 0,00 \\
\hline
\end{tabular}




\section{Approximations - Boundary conditions}

Boundary conditions are defined at the borders of the computation domain as follows:

1. At rigid walls, i.e. at the bottom and the sides of the marina, the openings and the shore, the standard wall function approach is applied, which relates the shear stress at the wall to the cell node velocity component parallel to the wall. All velocity components are set to zero.

2. Open sea boundaries are treated as "inlets", "outlets" or "openings", depending on the expected flow field, which is driven by the wind. For NE and E winds, the eastern, western and northern open sea boundary were set as "opening", "outlet" and "solid wall", respectively, while for NW and W winds, the eastern, western and northern open sea boundary were set as "outlet", "opening" and "solid wall", respectively. These conditions have been adopted for the following reasons: (i) there are no field data in the area of study to be used as boundary conditions, and (ii) they do not affect noticeably the flow field inside the computational domain and specifically in the area of marina.

3. The free surface is treated as a symmetry plane using the rigid-lid approximation; accordingly, the normal velocity component and the normal gradients of all other variables are set equal to zero. Moreover, the effect of the wind is applied only in the region of marina and not in the wider coastal area to reduce the effect of the open sea boundary conditions on the calculations in the region of marina.

The flow domain of the marina is very shallow with its horizontal dimensions (2000 m x $1000 \mathrm{~m}$ ) being much higher than the vertical (maximum water depth $=8.0 \mathrm{~m}$ ). Shallow flow domains require the implementation of structured grids, which permit the use of volume elements with high aspect ratios and provide a good control of grid density and volume element distribution. Thus, a structured computational grid consisting of approximately 350000 hexahedral elements, with grid refinement in the inner region of the marina, has been used in the calculations. This size of the grid has been chosen after a series of preliminary calculations, to ensure relatively grid independent results. The preliminary calculations have been performed for case $\mathrm{S} 1$ (i.e. with prescribed wind direction and velocity) and 4 grid sizes (consisting of approximately 250000, 350000, 450000 and 700000 elements). The minimum size of the grid, which shows maximum differences in the predicted velocity values less than $\pm 3 \%$ from the finest grid (700000 elements), has been selected.

\section{Flow characteristics in the outer region}

Calculated surface velocities in the whole calculation domain are shown in Fig.2 for the series S4 and S4R. From the calculations, the following conclusions can be drawn:

1. In the region, which is relatively far from the open sea and the solid boundaries (see Fig.2), the flow behavior is independent of the presence of the walls of the marina and the openings.

2. In the region close to marina, the flow tends to move in a direction parallel to the main, northern solid wall, creating re-circulation regions in the eastern and western walls. The sizes of these regions, which depend on the direction and magnitude of the wind, are affected by the presence of the solid walls of the shore and the characteristics of the entrance. The width of the entrance is very small and does not permit the inflow-outflow of significant quantities of water, which could have lead to a significant flushing of waters.

3. Flow velocities at the surface range from $2.5 \%$ to $2.7 \%$ of the wind velocity, which are in satisfactory agreement with the value $3 \%$ encountered in the literature (Koutitas and O'Connor, 1980). The highest values are observed for the cases of $\mathrm{W}$ and $\mathrm{E}$ winds, where the wind direction is parallel to the main northern solid wall of the marina. The depth-averaged velocities are equal to approximately $85 \%$ of their corresponding values at the surface.

\section{Flow characteristics in the inner region}

Calculated surface velocities for series S4-S4R are shown in Figs. 3 and 4, at water depths $0.00 \mathrm{~m}$ (surface layer) and $2.00 \mathrm{~m}$ (bottom layer), respectively. From these figures and the processing of data, the following conclusions are drawn:

1. General flow pattern. The flow field shows the general behavior of coastal wind driven flows. It is influenced by the geometry (small dimension and location) of the entrance, which does not permit the inflow-outflow of large flow 

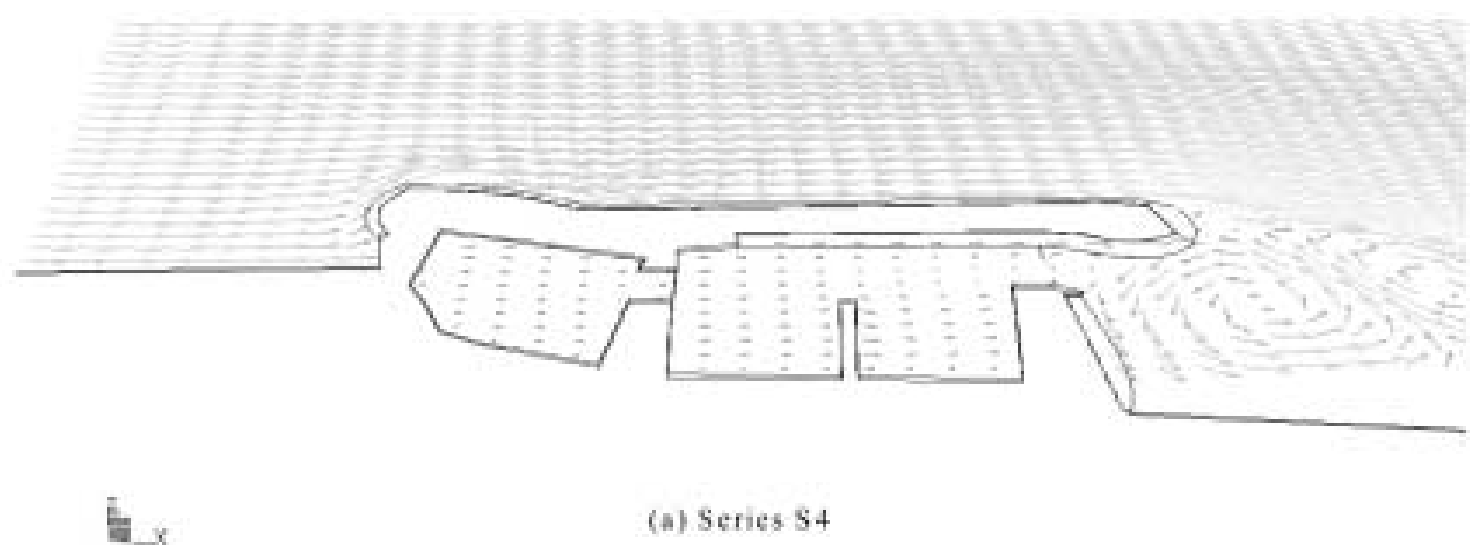

(a) Series $\mathrm{S} 4$

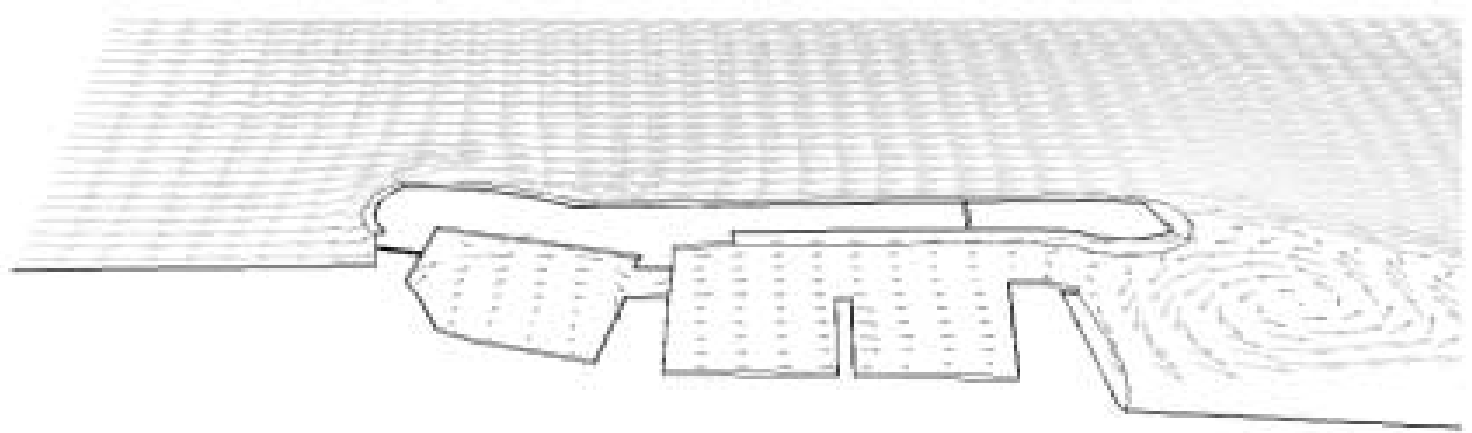

(b) Series $\mathrm{S} 4 \mathrm{R}$

Figure 2. Surface velocities in the region of marina

rates. In all 3 compartments (relatively far from the entrance) of the marina, two layers of flow are observed; a surface layer, which follows the direction of the wind and a bottom layer flowing in the opposite direction. The heights of the two layers are relatively constant in the 3 compartments and the flow shows a relatively $2-\mathrm{D}$ behavior. Flow velocities at the surface range from $0.3 \%$ to $0.5 \%$ of the wind velocity. These values are significantly lower than the values observed in the outer region due to the strong effect of the inner walls of marina.

2. Effect of the openings. Generally, the presence of the openings result in an increase of the flow rate through the marina (see Table 2) and the development of a 3-D flow field with the heights of the layers showing significant local variations. The effect of the opening $\mathrm{O} 1$ is very important, while the effect of the opening $\mathrm{O} 2$ is only of local and minor importance. This behavior is due to the orientation and the position of these openings with relation to the entrance. Opening $\mathrm{O} 1$ has a direction parallel to the main direction of the flow in the entrance and is located far from the entrance, while opening $\mathrm{O} 2$ has a direction perpendicular to the main direction of the flow in the entrance and is located very close to the entrance.

For NE and E winds (series S1R and S3R), the surface current of flow enters into compartment 3 via the entrance and follows a path approximately parallel to northern wall. A significant part of flow leaves immediately the marina via the opening $\mathrm{O} 2$, thus creating a significant degree of short-circuiting, while the 


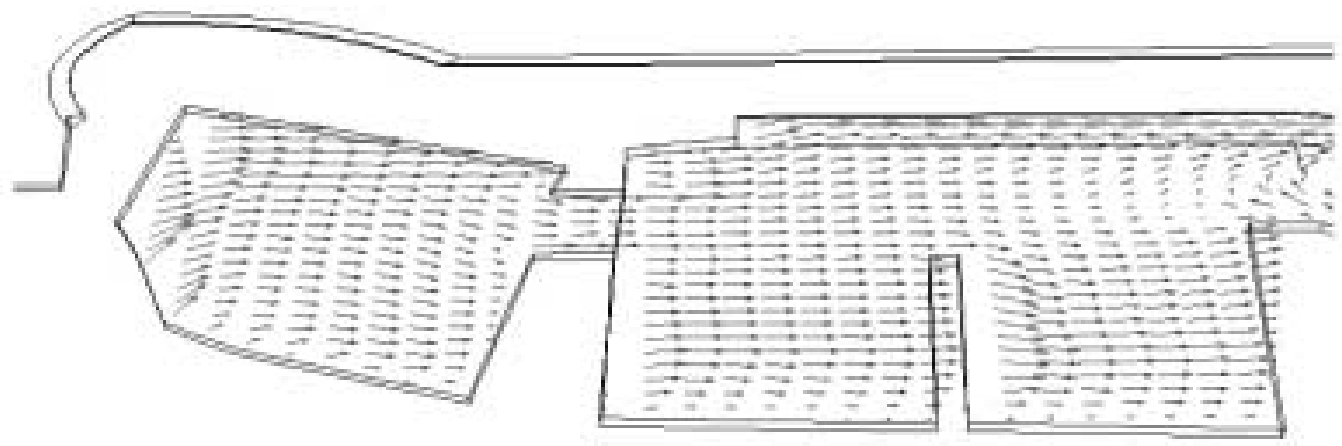

(a) Series S4

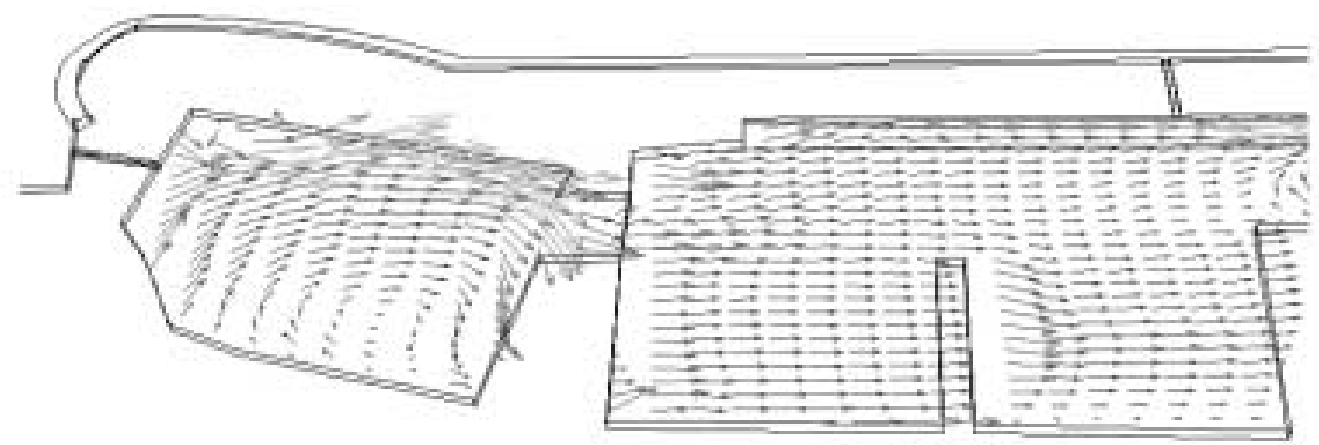

(b) Series S4R

Figure 3. Velocity field - Surface layer

rest of the flow passes through the compartments 2 and 1, respectively, and then exits the marina via the opening $\mathrm{O} 1$. The bottom current follows an opposite direction and leaves the marina via the entrance. The main effects of the opening, mainly of $\mathrm{O} 1$, are (a) the increase of the magnitude of velocities and (b) the reduction of the renewal time (see 3.6), due to the increase of the flow rate passing through the inner part of the marina.

For NW and W winds (series S2R and S4R, see Fig.3b), the surface current of flow enters to compartment 1 via the opening $\mathrm{O} 1$ and creates a large re-circulation region occupying the whole volume of the compartment. Then, it passes through the compartments 2 and 3 and follows a path approximately parallel to northern wall of compartment 3 . The flow, which enters in the marina via the opening $\mathrm{O} 2$, meets the main water stream and both water flows leave the marina following a short-circuiting route. The bottom current follows an opposite direction. The effects of the opening, mainly of $\mathrm{O} 1$, are similar, but more pronounced than in the cases of NW and W winds.

Calculations have been repeated without the opening O2. The effect on the results was not significant, being restricted in the area of the opening $\mathrm{O} 2$ and the entrance.

In Table 2 the flow rates in the opening O1, $\mathrm{Q}_{1}$, and in the opening 1-2 in the direction of the wind, $\mathrm{Q}_{1-2}$, are shown. The sign of these quantities are the same with the signs of the velocities, i.e. positive quantities means that the flow is directed eastwards. 
Table 2. Flow rates in the opening $\mathrm{O} 1$ and in the compartment $1\left(\mathrm{~m}^{3} /\right.$ day $)$

\begin{tabular}{|c|c|c|c|}
\hline Series & $\mathbf{Q}_{\mathbf{1}}$ & $\mathbf{Q}_{\mathbf{1 - 2}}$ & $\mathbf{Q}_{\mathbf{1}} / \mathbf{Q}_{\mathbf{1 - 2}} \mathbf{( \% )}$ \\
\hline S1 & - & -8338 & 0 \\
\hline S2 & - & +9158 & 0 \\
\hline S3 & - & -10498 & 0 \\
\hline S4 & - & +10454 & 0 \\
\hline S1R & -13133 & -17798 & 74 \\
\hline S2R & +12269 & +19570 & 63 \\
\hline S3R & -17971 & -21600 & 83 \\
\hline S4R & +14861 & +23717 & 63 \\
\hline
\end{tabular}

From the figures of Table 2 the following can be depicted:

1. The values of $\mathrm{Q}_{1}$ range from $63 \%$ to $83 \%$ of the $\mathrm{Q}_{1-2}$. The higher values are observed for the NW and $\mathrm{W}$ winds, which permit the inflow into compartment 1 through the opening O1.

2. The values of $\mathrm{Q}_{1-2}$ increase by more than $100 \%$, when the opening $\mathrm{O} 1$ is used.

\section{Renewal times}

\section{Total theoretical renewal time}

The theoretical renewal (or detention) times in the compartments $\Theta_{1}, \Theta_{2}$ and $\Theta_{3}$, respectively, can be calculated by the following equations:

$$
\Theta_{1}=\frac{V_{1}}{Q_{1-2}}, \Theta_{2}=\frac{V_{2}}{Q_{2-3}}, \Theta_{3}=\frac{V_{3}}{Q_{E N T}}
$$

where $\mathrm{Q}_{1-2}, \mathrm{Q}_{2-3}$ and $\mathrm{Q}_{\mathrm{ENT}}$ are the average flow rates of each layer in the openings 1-2, 2-3 and in the entrance (ENT), respectively.

The (total) theoretical renewal time in the marina, $\Theta$, can be calculated by summing up the detention times in all the compartments, i.e.:

$\Theta=\Theta_{1}+\Theta_{2}+\Theta_{3}$

These theoretical times, which are calculated and shown in Table 3, may give an indication on the effect of the openings on the renewal of waters. It is concluded, therefore, that the use of the opening results to a reduction of the total renewal time, which ranges from 8.4 to $31.5 \%$.

Theoretical detention time in the first compartment As expected and shown in the flow field results (see Figs.3 and 4), significant water renewal problems are observed mainly in the first compartment without the opening O1. In this compartment a theoretical detention time $\left(\Theta_{1}\right)$, which is equal to the theoretical flushing time, can be calculated for the flow stream flowing in the direction of the wind by the following relationship:

$$
\Theta_{1}=\frac{V_{1 W}}{Q_{1-2}}
$$

where $\mathrm{V}_{1 \mathrm{w}}$ is the volume of the compartment 1 occupied by the water flowing in the direction of the wind.

In Table 4 the values of $\Theta_{1}$ are shown with the corresponding reductions.

The figures of Table 4 show that the use of the opening results to a significant reduction of $\Theta_{1}$, which ranges from 42 to $47 \%$.

\section{Paths and travel time of a fluid particle}

In Fig.5 the paths of a fluid particle, which is

Table 3. Total theoretical flushing times (day)

\begin{tabular}{|c|c|c|c|c|}
\hline Series & $\boldsymbol{\Theta}$ & Series & $\boldsymbol{\Theta}$ & Reduction (\%) \\
\hline S1 & 3.36 & S1R & 2.30 & 31.5 \\
\hline S2 & 2.86 & S2R & 2.62 & 8.4 \\
\hline S3 & 2.01 & S3R & 1.80 & 10.4 \\
\hline S4 & 2.27 & S4R & 1.80 & 20.7 \\
\hline
\end{tabular}




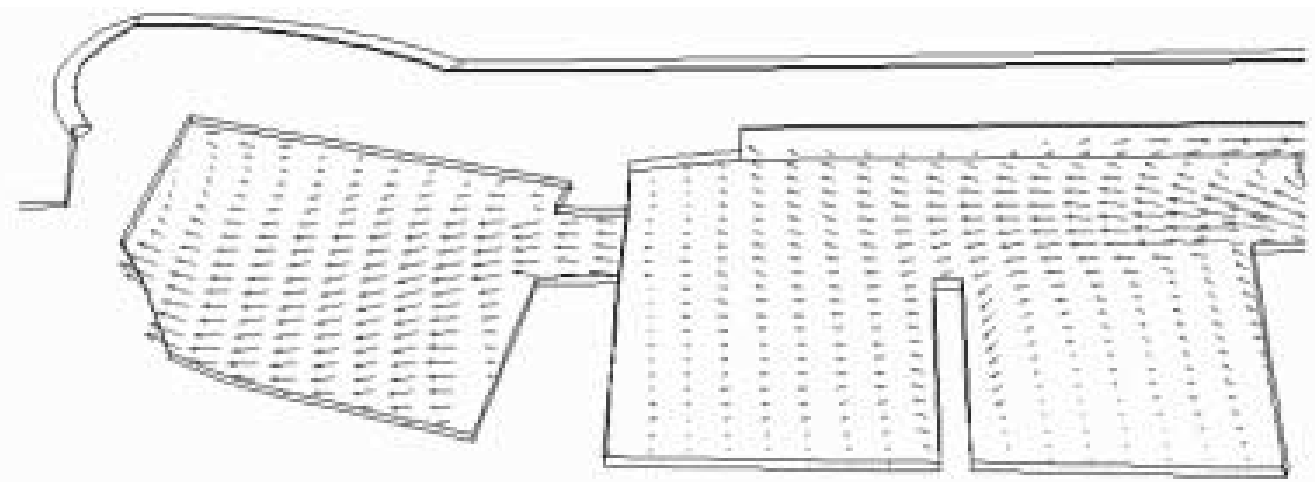

(a) Series S4

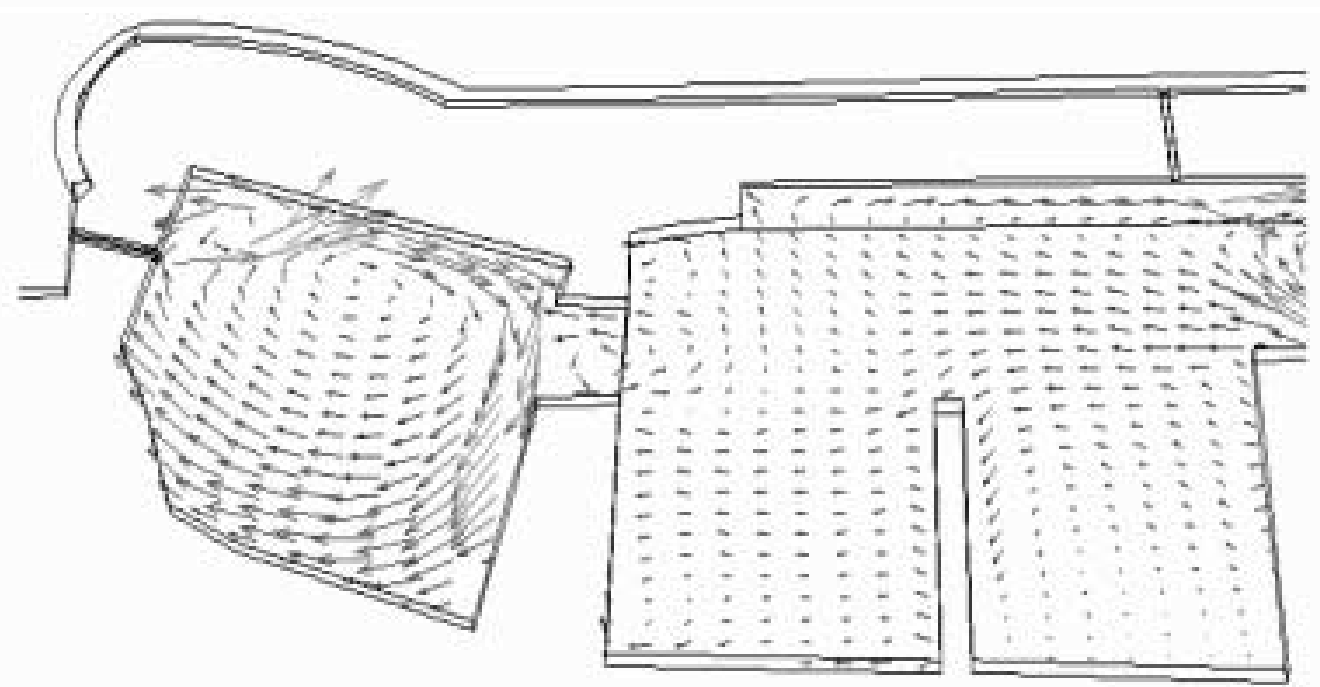

(b) Series S4R

Figure 4. Velocity field - Bottom layer

located at point A (at the surface) in the compartment 1, are shown for $\mathrm{W}$ wind (series $\mathrm{S} 4$ and S4R). Each path consists of a series of successive positions, whose distance is equal to 30 minutes. Thus, the travel time of the particle towards the entrance (point C) can be easily estimated.

The time of travel for cases S4 and S4R were cal- culated equal to 22 and 14.5 hours, respectively, i.e. the use of the opening O1 results to a $34 \%$ reduction of the travel time.

\section{Characteristics of the computations}

All calculations have been performed with a single PC with the following configuration: $1.6 \mathrm{GHz}$

Table 4. Theoretical flushing times in compartment 1(day)

\begin{tabular}{|c|c|c|c|c|}
\hline Series & $\boldsymbol{\Theta}_{\mathbf{1}}$ & Series & $\boldsymbol{\Theta}_{\mathbf{1}}$ & Reduction (\%) \\
\hline S1 & 1.82 & S1R & 1.02 & 44 \\
\hline S2 & 1.65 & S2R & 0.93 & 44 \\
\hline S3 & 1.44 & S3R & 0.84 & 42 \\
\hline S4 & 1.45 & S4R & 0.77 & 47 \\
\hline
\end{tabular}



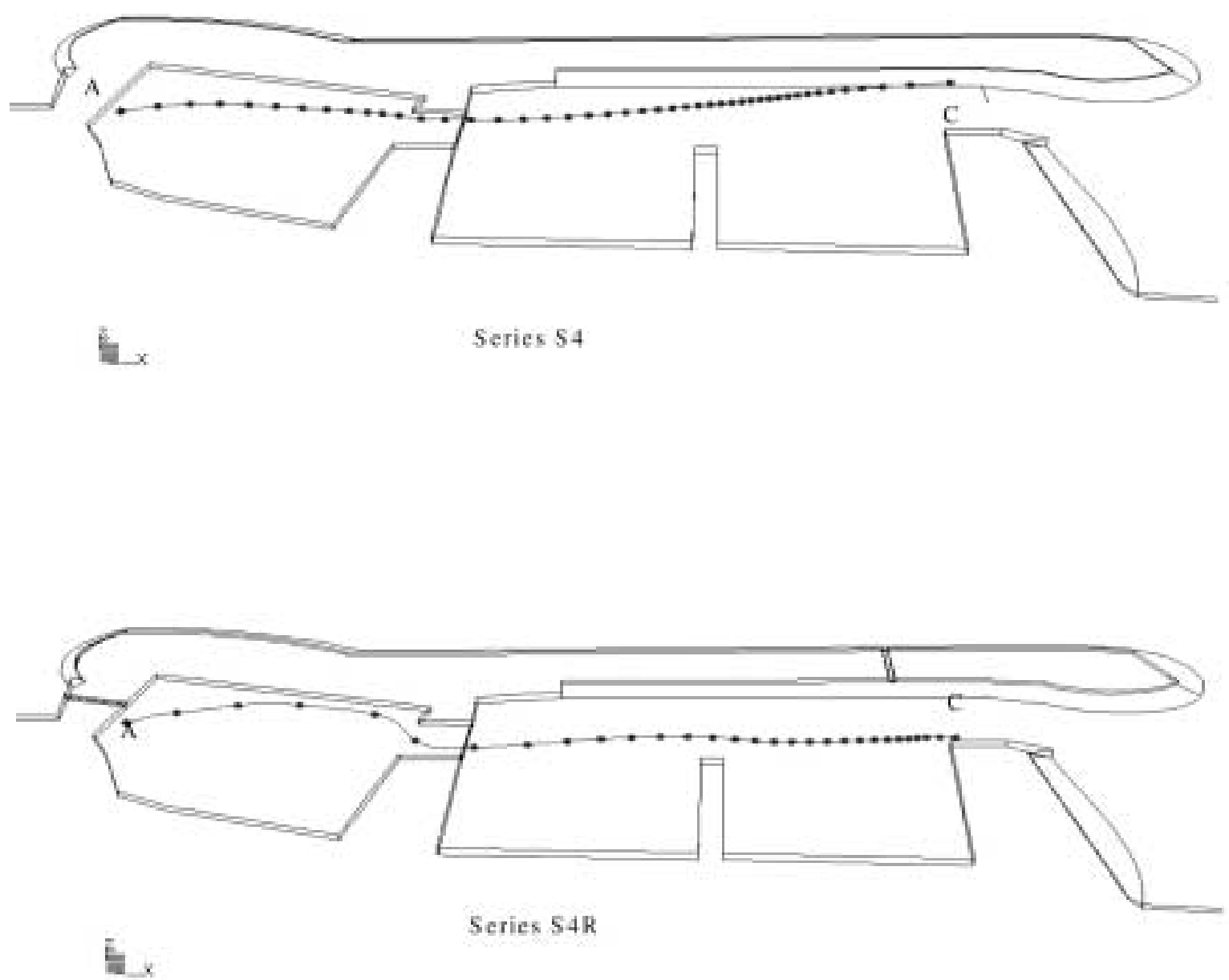

Series 54 R

Figure 5. Path of fluid particle for $\mathrm{W}$ wind

P4 processor, $512 \mathrm{Mb}$ RAM and a $40 \mathrm{~Gb}(7200$ RPM) hard disk drive. The average time-step used in the calculations was $15 \mathrm{~min} .500$ iterations were required to achieve steady-state conditions, corresponding to a total simulation time of 5.2 days. The total computer time was approximately 36 hours.

\section{CONCLUSIONS}

From the present work the following conclusion are drawn:

1. The flow field in the marina shows the general behavior of coastal, wind driven flows, being strongly influenced by the characteristics of the entrance of the marina. The small dimension and the location of the entrance do not permit the inflow or outflow of significant flow rates, thus resulting to high values of flushing times.

2. The use of two openings has been investigated (see Fig.1). The first opening plays a very important role, while the effect of the second opening is only of local and minor importance. This behavior is due to the orientation and the position of these openings with relation to the entrance.

3. The use of the first opening results to significant increase of the flow rate passing through the marina, increase of the magnitude of velocities and reduction of the flushing times. The total flushing time decreases by 8.4 to $31.5 \%$, the flushing times in compartment 1 by 
42 to $47 \%$ and the travel time of a particle located at compartment 1 by $25 \%$ to $34 \%$.

4. The use of the second opening creates a significant short-circuiting path of the flow between the opening and the entrance.

The Ministry of Transportation and Public Works of Cyprus has decided to implement the first opening in the configuration of marina. The project is currently in the phase of construction.

\section{ACKNOWLEDGEMENTS}

The authors would like to thank the Ministry of Transportation and Public Works of Cyprus for providing the financial support.

\section{REFERENCES}

AEA Technology (1999), CFX-5.3 User Guide, 8.19, Harwell, Didcot, Oxfordshire, OX110RA, UK.

Cardwell R.D. and Koons R.R. (1981), Biological Considerations for the Siting and Design of Marina and Affiliated Structures in Puget Sound, Technical Report No. 60, State of Washington, Department of Fisheries.

EPA (1993a), Environmental Engineering for Small Boat Basins, Engineering Manual, EM1110-2-1206.

EPA (1993b), Guidance Specifying Management Measures for Sources of Non-point Pollution in Coastal Waters, EPA 840-B-92-002.

EPA (1996), Managing Non-point Source Pollution from Boating and Marinas, Pointer No. 9, EPA841-F-96-004I.

EPA (2001), National Management Measures Guidance to Control Non-point Source Pollution from Marinas and Recreational Boating, EPA841-B-01-005.

Fisher H.B., List E.J., Koh R.C.Y., Imberger J. and Brooks N.H. (1979), Mixing in Inland and Coastal Waters, Academic Press, Inc., New York, N.Y.

Hilton A.Ch., McGillivary D.L. and Adams E.E. (1998), Residence Time of Freshwater in Bostons Inner Harbor, J. of Waterway, Port, Coastal and Ocean Engineering, ASCE, 124, 82-89.

Koutitas C. and O'Connor, B. (1980), Modeling Three-Dimensional Wind-Induced Flows, J. of Hydraulics Division, ASCE, 11, 1843-1865.

Officer C. B. (1976), Physical oceanography of estuaries (and associated coastal waters), John Willey \& Sons, Inc., New York, N.Y.

Schwartz R.A. (1989), The flushing characteristics of Hillarys boat harbor, M. Eng. Sc. thesis, University of Western Australia, Centre for Water Research Reference ED, 259 RS.

Schwartz R.A. and Imberger J. (1988), Flushing behavior of a coastal marina, In: Proceedings 21st International Coastal Engineering Conference, Spain, ED 439.

Stamou A.I., Falconer R.A., Hakimzadeh H. and Pipilis K.G. (1997), Optimization of Marina Design utilizing Mathematical Models, In: Proceedings of the National Conference for the Management of Water Resources in Islands and Coastal Areas, Syros, Greece, pp.183-189.

Stamou A I., Kapetanaki M., Christodoulou G., Rajar R. and Cetina M. (2001), Mathematical Modeling of Flow and Pollution in Marinas, In: Proceedings of the 7th Int. Conf. on Environmental Science and Technology, Syros, Greece, pp.830-837.

Tetra Tech (1988), Rive St. Johns phase II canal System Water Quality Model Study, Tetra Tech Report TC-36804.

Yin J., Falconer R.A., Pipilis K. and Stamou A. I. (1998), Flow Characteristics and Flushing Processes in Marinas and Coastal Embayments, In: Proceedings of the 1st Int. Conf. on Maritime Engineering and Ports, Genoa, pp.87-98. 